\title{
Adaptations of frogs to survive freezing
}

\author{
Jack R. Layne, $\mathrm{Jr}^{1}$, Richard E. Lee, $\mathrm{Jr}^{2}$ \\ ${ }^{1}$ Department of Biology, Slippery Rock University, Slippery Rock, Pennsylvania 16057, USA \\ ${ }^{2}$ Department of Zoology, Miami University, Oxford, Ohio 45056, USA
}

\begin{abstract}
Five species of frogs from North America survive extensive freezing of their body fluids to temperatures as low as $-8^{\circ} \mathrm{C}$ for periods lasting at least $2 \mathrm{wk}$. These frogs hibernate in leaf litter where subzero temperatures commonly occur during the winter. The onset of freezing triggers liver glycogenolysis and the production of high concentrations of glucose or glycerol (to $100 \times$ normal) that functions as a cryoprotectant against freezing injury. Concomitantly the release of the latent heat of crystallization as body water freezes promotes the continued function of the cardiovascular system for many hours and serves to distribute glucose throughout the body. The water content of major organs is reduced by $50 \%$ or more during the first $24 \mathrm{~h}$ of freezing, with the water being relocated and frozen in other body spaces. Organ dehydration functions to concentrate cryoprotectant and to reduce mechanical damage by ice during freezing. As freezing progresses, breathing, heart beat, and most other vital functions cease, but reanimation occurs within a few hours after thawing. The evolution of freeze tolerance in these animals illustrates the highly flexible capacities of frogs to adapt to stressful environments.
\end{abstract}

KEY WORDS: Cryoprotection · Freeze tolerance - Frogs - Overwintering · Physiology

\section{INTRODUCTION}

Frogs generally attain body temperatures that conform with their immediate surroundings. This feature seemingly should prevent habitation of cold climates due to the risk of lethal freezing during winter; however, many species survive at mid and high latitudes because they are capable of living in frost-free hibernacula (e.g. bottom of ponds). Moreover, recent studies have revealed that at least 5 species from North America - Hyla chrysoscelis (Schmid 1986, Costanzo et al. 1992b), Hyla versicolor (Schmid 1982), Pseudacris crucifer (Schmid 1982), Pseudacris triseriata (Storey \& Storey 1987), and Rana sylvatica (Schmid 1982) - survive freezing of their internal body fluids to temperatures as low as $-8^{\circ} \mathrm{C}$ in winter. This unique adaptation allows these species to hibernate beneath the surface of forest floor litter where exposure to subzero temperatures is inevitable.

Freeze tolerance is an adaptive response that allows a species to cope with natural episodes of freezing of body fluids. This tolerance implies the existence of both a definite risk of freezing in nature and biochemical and physiological adaptations for coping with the formation of ice in body tissues. The first scientific demonstration of freeze tolerance in vertebrates was offered only recently by Schmid (1982). Interestingly, previous investigators studying the cryobiology of Rana sylvatica (Miller \& Dehlinger 1969, Lotshaw 1977) and Pseudacris triseriata (MacArthur \& Dandy 1982) concluded that freeze tolerance was insufficiently developed in these species to meet most challenges during winter. The conclusions of these investigators were based on experimental protocols that exceeded the natural capacities of these frogs to survive freezing.

\section{THE HIBERNACULUM AND ITS MICROCLIMATE}

Limited information exists about natural hibernacula used by freeze-tolerant frogs (Pinder et al. 1992). While exploring the Canadian Arctic, Samuel Hearne (1911) found frozen frogs during the winter, which he described as being solidly frozen but which promptly revived upon thawing near a campfire. The identity of the species was not clearly indicated by Hearne, but Pseudacris triseriata and Rana sylvatica are the only anuran species inhabiting the region $\left(61^{\circ} \mathrm{N}\right)$ that was 
explored. Naturalist John Burroughs (1914) found an overwintering $R$. sylvatica resting under leaf litter in New York, USA, at the end of December The frog still occupied this site 3 mo later despite its surroundings having undergone extensive freezing.

Schmid (1986) measured the temperature beneath leaf litter near hibernacula used by Hyla versicolor in Minnesota, USA. The hibernaculum temperature remained below $-1^{\circ} \mathrm{C}$ during most of December and January and it reached a minimum temperature of only $-7^{\circ} \mathrm{C}$ during this period. Freeze-thaw cycles likely occur in conjunction with fluctuations in weather and snow cover Additional data are needed on hibernacula and their microclimates in order to understand better the conditions experienced by overwintering frogs.

\section{FREEZING OF INTERNAL BODY FLUIDS}

The onset of ice nucleation within body tissues is due to either inoculative freezing or spontaneous ice nucleation within the frog. Inoculative freezing is likely under natural conditions because frog skin in contact with external ice readily allows transcutaneous ice growth, causing the freezing of frogs when temperatures fall below the melting point of body fluids, ca $-0.5^{\circ} \mathrm{C}$ (Layne et al. 1990, Layne 1991). This probably occurs frequently in nature because these frogs likely require moist hibernacula (Storey \& Storey 1992).

Occasional drought may reduce the likelihood for inoculative freezing. In this situation overwintering frogs would freeze only when they cool below the supercooling limit of their body fluids. This temperature is uniformly high in all frogs (Schmid 1982, Storey \& Storey 1986, Layne 1995a, b). Ice nucleation at high subzero temperatures presumably is beneficial because it allows the ice lattice to grow relatively slowly at these higher temperatures and consequently provides time for the frogs to activate fully their cryoprotective responses (see section 'Cryoinjury and cryoprotection' below). However, frogs are highly susceptible to dehydration when they occupy dry environments and they probably select hibernacula that remain moist throughout the winter.

The ice nucleating agent responsible for limiting the supercooling capacity of frogs has been the subject of several recent studies. Rana sylvatica possess a plasma factor, presumably proteinaceous, that triggers ice nucleation at temperatures near $-8^{\circ} \mathrm{C}$ (Wolancyzk et al. $1990 \mathrm{a}, \mathrm{b}$, Storey et al. 1992a), whereas the digestive tracts of these frogs contain bacteria that can initiate freezing at temperatures ranging between -2 and $-3^{\circ} \mathrm{C}$ (Lee et al. 1992). The close correspondence between the latter temperatures and the supercooling limit of frogs suggests that these bacteria are more likely triggers for the onset of spontaneous freezing than the aforementioned plasma agent. The supercooling limit of individual organs also lends support to the contention that bacteria regulate the supercooling potential of whole frogs (Layne 1995a). Spontaneous freezing of the entire frog should be triggered whenever its body temperature reaches the crystallization temperature of the organ or body fluid possessing the most potent ice nucleators. Among the many organs and body fluids comprising a frog's body, only the intestine and skin have crystallization temperatures as high as a whole frog $\left(\mathrm{ca}-3^{\circ} \mathrm{C}\right)$. Moreover, both organs are host to large bacterial populations that potentially could induce ice crystal formation.

At relatively warm subzero temperatures ice preferentially forms in the extracellular compartment, with intracellular crystallization being a rare and generally lethal event (Mazur 1984). These conclusions are based on studies with human and mammalian tissues. Similar limitations are believed to exist for freezetolerant frogs (Storey \& Storey 1992). Studies on liver slices from Rana sylvatica suggest that ice forms only in the extracellular compartment at ecologically relevant temperatures (Storey et al. 1992b). However, the fat body cells of the goldenrod gall fly Eurosta solidaginis freeze internally whenever ice forms in the body fluids of these freeze-tolerant insects (Lee et al. 1993). Since a similar situation could exist with some cells of freeze-tolerant frogs, further studies are needed to evaluate the distribution of ice between the extracellular and intracellular compartments.

Ice accumulates progressively in body fluids of frogs freezing at high subzero temperatures until an equilibrium is attained (Fig. 1; Layne \& Lee 1987, 1989). The rate of ice formation is affected by many factors,

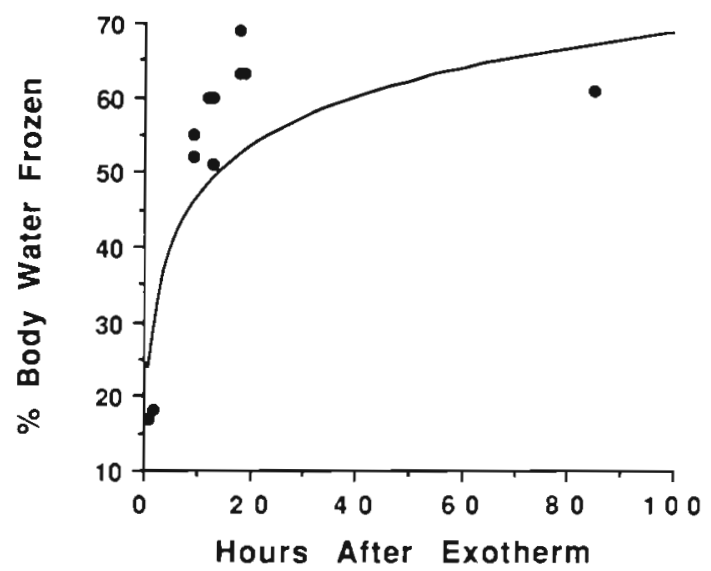

Fig. 1. Rana sylvatica. Time course of ice accumulation in frogs freezing at -2 to $-3^{\circ} \mathrm{C}$. Ice contents were measured by calorimetry (from Layne \& Lee 1987). Exotherm refers to the sudden release of the latent heat of fusion due to the onset of freezing 
including body size and temperature. Surrounding insulation, including leaf litter and snow cover, greatly slows the rate of internal ice formation by conserving the latent heat of fusion and maintaining body temperature near its freezing point for many hours (Costanzo et al. 1991a). Final ice contents as high as $70 \%$ of the body water content can be tolerated by freeze-tolerant frogs (Costanzo et al. 1993a). Body tissues, however, have distinctly different capacities to accumulate ice, with the greatest amounts forming in peripheral tissues. For example, $17 \%$ more of the total tissue water freezes in the hindlegs than in the body trunk at $-2.5^{\circ} \mathrm{C}$ (Layne \& Lee unpubl. data).

\section{CRYOINJURY AND CRYOPROTECTION}

Freezing of extracellular fluids disrupts many cell functions and causes death without proper protective measures. As ice forms extracellularly, solutes are excluded from the growing ice lattice and concentrated in the unfrozen solution (Mazur 1984). This hypertonic fluid osmotically draws water from cells in proportion to the amount of ice forming, thereby causing potentially lethal complications due to cell shrinkage, destabilization of cell membranes and proteins, and failure of cell metabolism and homeostasis.

Cryoprotectants are substances that eliminate the injurious effects of freezing. Many substances have this capacity, including polyhydric alcohols and low molecular weight sugars, especially when present in relatively high concentrations. Two cryoprotectants, glucose and glycerol, are known in freeze-tolerant frogs. During the autumn these frogs store large quantities of liver glycogen to serve as the source for their cryoprotectant (Storey \& Storey 1992). Upon initiation of internal freezing, this polysaccharide is converted into glucose via glycogenolysis (Storey \& Storey 1984 1985a, Costanzo et al. 1993a). The magnitude of this response is substantially lower during the spring than during the fall or winter, owing to pronounced depletion of glycogen reserves following the emergence of frogs from hibernation (Storey \& Storey 1987, Costanzo et al. 1993a, Layne 1995b). Indeed, optimally conditioned Rana sylvatica respond to the onset of freezing by increasing their blood glucose from 2-4 to $250 \mu \mathrm{mol}$ $\mathrm{ml}^{-1}$. All species but Hyla versicolor distribute large quantities of glucose to their body tissues, with the greatest amount going to major organs rather than to the skin and limb skeletal muscles (Storey \& Storey 1984). H. versicolor is exceptional because it converts most of its glucose into glycerol for distribution to its body tissues (Storey \& Storey 1985b).

The cryoprotective role of glucose and glycerol in freeze-tolerant frogs has been inferred from the mas- sive mobilization of these substances in response to freezing Glycerol is routinely used for cryopreservation and naturally by freeze-tolerant insects (Mazur 1984, Lee \& Denlinger 1991); however, glucose is only modestly effective in the cryoprotection of mammalian tissues. Consequently several studies have directly tested the hypothesis that glucose functions as a cryoprotectant during freezing In vitro studies of cardiac muscle strips (Canty et al. 1986) and red blood cells (Costanzo \& Lee 1991) from Rana sylvatica demonstrated enhanced survival of freezing in the presence of large quantities of glucose. Another study found that lymphatic injections of exogenous glucose decreased hemolysis and neuromuscular injury in $R$. sylvatica during otherwise injurious rates of freezing (Costanzo et al. 1991b). Furthermore, the increased cryoinjury associated with rapid cooling was linked with decreased glucose levels in liver, heart, muscle, eye, and brain, which were presumably a consequence of insufficient time for glucose mobilization from liver glycogen and premature cessation of cardiovascular function due to rapid ice growth throughout the frog (Costanzo et al. 1992a). More recently, injections of exogenous glucose greatly extended the lower limit of freeze tolerance of $R$. sylvatica during the spring by counteracting their diminished capacity to mobilize glucose (Costanzo et al. 1993a).

Cryoprotectant likely functions in a multifaceted fashion (Mazur 1984, Storey \& Storey 1992). Glucose reduces both the amount of cellular dehydration and the ice content of the vascular space in liver slices from Rana sylvatica (Storey et al. 1992b). Glucose loading reduces the total amount of ice forming at a specific freezing temperature (Costanzo et al. 1993a). This reduction is mostly associated with the effect of solute concentration on the final ice content of an aqueous solution. Using the theoretical relationship described by Claussen \& Costanzo (1990), the predicted ice content of a $250 \mathrm{mOsm}$ solution is less than the predicted ice content of a 500 mOsm solution, especially at higher subzero temperatures (Fig. 2A). Correspondingly, seasonal increases in glucose mobilization between the spring and fall proportionately reduce the total body ice content of frogs (Fig. 2B). There also appear to be differences in the potential of glucose to protect human versus frog red blood cells during freezing, which suggests fundamental differences between their cell membranes (Costanzo \& Lee 1991). This is supported by the fact that the plasma membrane of $R$. sylvatica transports glucose more efficiently than does the plasma membrane of $R$. pipiens, a freeze-intolerant frog (King et al. 1993).

Another major mechanism of cryoprotection is the dehydration and relocation of substantial amounts of water from major organs to extravascular cavities and 


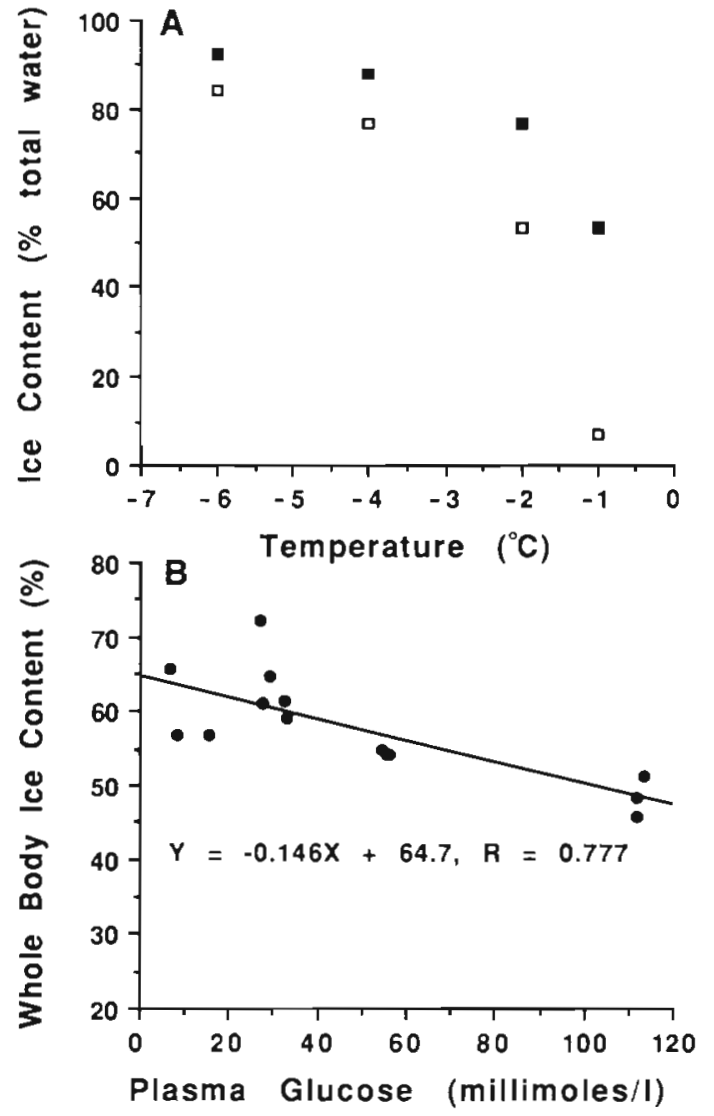

Fig. 2. Rana sylvatica. Relationship (A) between temperature and final ice content of 250 and 500 mOsm solutions, and (B) between plasma glucose levels and ice content of frogs frozen at -2 to $-3^{\circ} \mathrm{C}$ for $24 \mathrm{~h}$. Solid boxes and open boxes denote ice contents of 250 and 500 mOsm solutions, respectively. In (B) the ice content and plasma glucose values were measured for R. sylvatica collected from western New York

spaces during freezing (Lee et al. 1990, 1992). Because mechanical damage to the vasculature is a major problem during freezing of organs (Rubinsky \& Pegg 1988), removal of water from organs in these frogs may prevent mechanical injury associated with freezing (Lee et al. 1990, 1992). The extent of dehydration varies among organs, with the liver losing more than $50 \%$ of its initial water while skeletal muscles lose only 20 to $30 \%$. Such dramatic changes in tissue water undoubtedly affect ice formation and may explain previously noted differences in ice formation among different body regions. The role of organ dehydration is supported by the observation that rapidly frozen frogs having only partial organ dehydration experience greater levels of cryoinjury (Costanzo et al. 1992b). Interestingly, lymphatic injections of glucose do not influence the magnitude of dehydration experienced by individual organs but do induce large changes in their glucose contents (Costanzo et al. 1993a).

\section{PHYSIOLOGICAL RESPONSES TO FREEZING}

Freezing induces profound changes in the function of major physiological systems, including loss of the capacity to exchange and transport respiratory gases, increasing reliance on anaerobiosis to support ATP production, loss of water from the blood, loss of tissue compliance, loss of nutrient delivery, loss of internal homeostasis, and elevation of osmolality and electrolyte levels in unfrozen body fluids. These events often are interrelated consequences of freezing and the changing performance of systemic functions, so assigning causal relationships is not a simple task. Regardless, the end result is that the physiological functions of major body systems are arrested during freezes lasting more than a few hours.

The effect of freezing and thawing on the cardiovascular system is well documented (Lotshaw 1977, Layne et al. 1989, Layne \& First 1991) and illustrates the challenges associated with internal freezing, Under laboratory conditions, as a frog cools to body temperature of -2 to $-3^{\circ} \mathrm{C}$, the heart rate slows to approximately 4 beats $\min ^{-1}$ (Fig. 3A, B). When spontaneous freezing commences, body temperature abruptly rises to the melting point; this temperature increase is accompanied by a sudden increase in heart rate. Both heart rate and body temperature remain elevated during the initial hours of freezing. The heart rate declines slowly during the next few hours in Rana sylvatica until arrest occurs nearly $24 \mathrm{~h}$ after the onset of freezing (Layne et al. 1989). Interestingly, freeze-tolerant and freezeintolerant frog species differ very little in this overall sequence (Lotshaw 1977, Costanzo et al. 1993b), which further attests to the fact that freezing is not instantaneously lethal to most frog species. However, postfreeze recovery of the cardiovascular system following prolonged, extensive ice formation seemingly is unique to freeze-tolerant species (Layne et al. 1989 Layne \& First 1991).

As respiratory gas exchange and delivery declines and ultimately fails, freeze-tolerant frogs sustain cellular energy demands anaerobically (Storey \& Storey $1984,1985 b)$. The loss of systemic functions naturally reduces energy demands, but this reduction does not compensate for all the complications that arise from reliance on anaerobic glycolysis. Total energy charge consequently declines by much as $50 \%$ in Rana sylvatica during a $3 \mathrm{~d}$ freeze (Storey \& Storey 1984)

Thawing causes body temperature to rise slowly and liquid water to return progressively to body fluids. The heart resumes beating during these initial hours of thawing (Fig. 3C, D). In Rana sylvatica, this happens as soon as 1 to $2 \mathrm{~h}$ after the onset of thawing, and normal heart rates are achieved within a few hours after the onset of thawing (Layne \& First 1991). Other bodily func- 

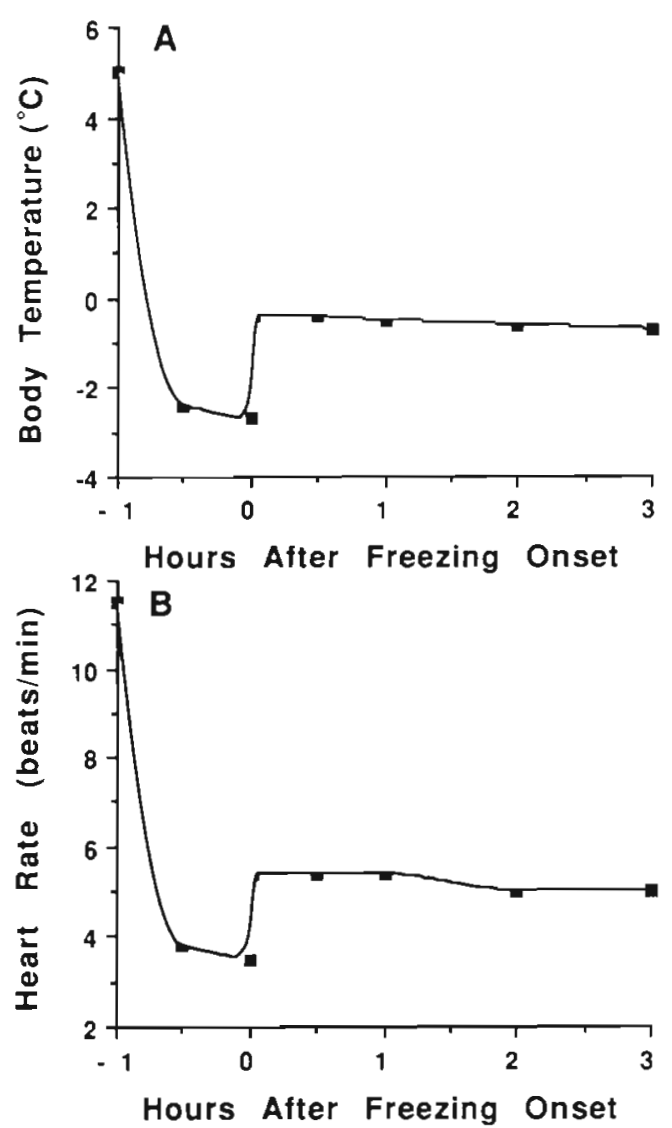

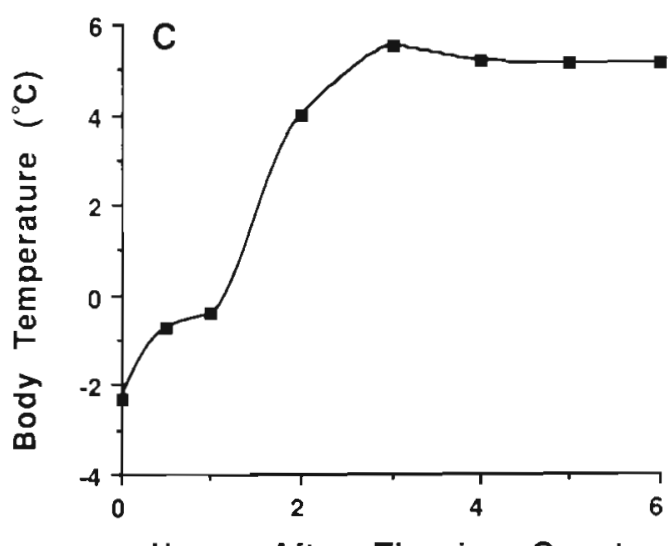

Hours After Thawing Onset

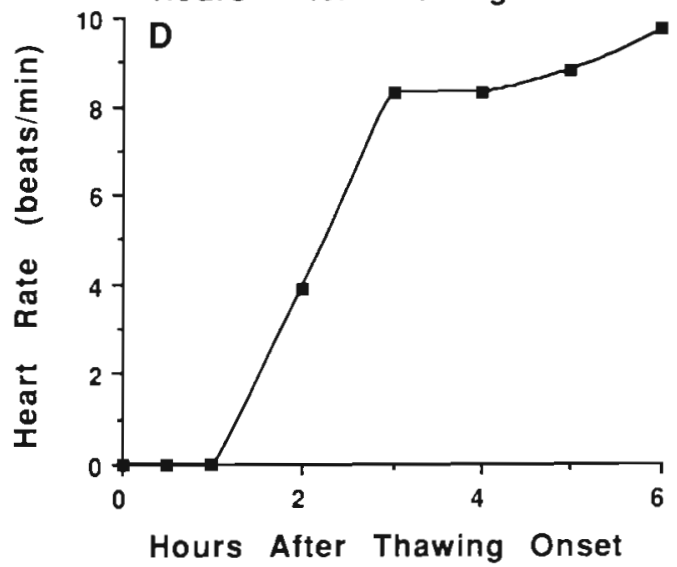

Fig. 3. Hyla versicolor. Profile for body temperature and heart rate during freezing and thawing of an adult frog from New York during the autumn. (A) and $(B)$ depict changes during freezing at $-2^{\circ} \mathrm{C} i(C)$ and $(D)$ depict changes during thawing at $5^{\circ} \mathrm{C}$

tions (breathing, excretion, nerve excitability, skeletal muscle contraction, and complex behaviors) slowly return during the ensuing hours (Layne \& First 1991, Kling et al. 1994). The rate of return is highly dependent on the temperature and duration of a freezing bout and on the rapidity of the thaw. For example, skeletal muscle contractility returns to normal more slowly following a $3 \mathrm{~d}$ freeze than after a $1 \mathrm{~d}$ freeze (Layne 1992), and body systems are reanimated more slowly when the rate of thawing is decreased (Layne \& First 1991).

\section{THE ECOLOGY AND EVOLUTION OF FREEZE TOLERANCE IN FROGS}

The ability of frogs to survive freezing in nature depends on the sufficiency of their tolerance limits to protect them from conditions in their hibernacula. Microclimate data are not sufficiently well known to permit accurate estimation of the frequency and duration of freezing bouts, especially given the substantial variations in weather that occur both annually and latitudinally. The current evidence suggests that freezing episodes are frequent and may be prolonged in some cases (Schmid 1986). Nevertheless, these frogs are often abundant in their respective natural communities so their tolerances are adequate to cope with stresses imposed by the winter environment.

Cell dehydration/rehydration, glycogenolysis/glycogenesis, and prolonged reliance on anaerobiosis are burdens on cellular functions that undoubtedly have energetic costs to freeze-tolerant frogs. Repeated freeze-thaw episodes deplete glucose reserves owing to persistent loss via renal excretion and greater utilization to rectify metabolic disturbances caused during freezing (Lee \& Costanzo 1993). The latter is evidenced by elevated aerobic metabolism during the postfreeze recovery period (Layne unpubl. data). The alternative strategy, freeze avoidance (e.g. selection of hibernacula that do not experience subzero temperatures), also has energetic costs that are incurred during burrowing to considerable depths and prolonged exposure to higher environmental temperatures. Presently, sufficient data are not available to compare the energetic costs of freeze tolerance and freeze avoidance in overwintering anurans. 
The evolution of freeze tolerance in frogs largely resulted from modification of phenotypic qualities involving their existing adaptations to cope with cold, dehydration, and hypoxia (Churchill \& Storey 1993, Costanzo et al. 1993b). Some freeze-intolerant frogs endure freezes lasting several hours and their skeletal muscles recover from freezing bouts lasting as long as 3 d (Lotshaw 1977, Layne 1992, 1993). Moreover, freeze-intolerant frogs tolerate exogenous doses of glucose leading to hyperglycemia (50-fold or more above normal levels), although this does not measurably enhance their ability to survive extensive freezing (Costanzo et al. 1993b, Layne unpubl. data). The evolution of freeze tolerance obviously involves fundamental phenotypic modifications that go beyond a high capacity to store glycogen and the subsequent mobilization of glucose during freezing.

The phylogenetic relationships of the freeze-tolerant frogs suggest that freeze tolerance evolved on several occasions. One species, Rana sylvatica, is a member of the family Ranidae, whereas the other 4 species belong to the family Hylidae. These families are evolutionarily separated by at least 60 million yr (Duellman \& Trueb 1986). A considerable degree of phylogenetic separation also exists among most of the freeze-tolerant hylids. The genera Pseudacris and Hyla both include freeze-tolerant species but most members of these genera lack this adaptation. Because these genera experienced phylogenetic separation no less than 27 million yr ago (Hedges 1986), freeze tolerance most likely evolved separately in these genera rather than in a common freeze-tolerant ancestor. The freezetolerant hylids ( $H$. chrysoscelis and $H$. versicolor), however, are very closely related and shared a common ancestor only $300000 \mathrm{yr}$ ago (Ralin et al. 1983). The evolutionary origin of $H$. versicolor entailed a transition from diploidy to tetraploidy within the $H$. chrysoscelis lineage. A major distinction exists in their cryobiology; the tetraploid is unique among anurans in using glycerol as a cryoprotectant. It has been speculated that the larger genome of $H$. versicolor has rendered it competitively superior to $H$. chrysoscelis (Ralin et al. 1983). Perhaps duplication of genetic information in the former species also fostered the evolution of its ability to use glycerol by allowing greater phenotypic flexibility in its biochemistry and cell biology.

The capacity to tolerate freezing probably is not restricted to just these 5 species in North America. Several related species with similar hibernation habits are found at mid-latitudes. Moreover, some frog species in Europe and Asia, especially close allies of Rana sylvatica, may have evolved freeze tolerance. Thus, freeze tolerance may occur commonly among frog species that must overwinter in terrestrial microhabitats subject to subzero temperatures.
Acknowledgements. This research was supported by grants from the National Institute of Health (1R15 DK-43958-01), the National Science Foundation (IBN-9305809), and the Faculty Development Council of Slippery Rock University. The authors are grateful to Jon P. Costanzo for his comments on a earlier draft of this manuscript.

\section{LITERATURE CITED}

Burroughs J (1914) The writings of John Burroughs VII. Signs and seasons. Houghton Miffin Co, Boston, p 48-49

Canty A, Driedzic WR, Storey KB (1986) Freeze tolerance of isolated ventricle strips of the wood frog, Rana sylvatica. Cryo-Lett 7:81-86

Churchill TA, Storey KB (1993) Dehydration tolerance in wood frogs: a new perspective on development of amphibian freeze tolerance. Am J Physiol 265:R1324-R1332

Claussen DL, Costanzo JP (1990) A simple model for estimating the ice content of freezing ectotherms. J therm Biol 15:223-231

Costanzo JP, Lee RE Jr (1991) Freeze thaw injury in erythrocytes of the freeze-tolerant wood frog, Rana sylvatica. Am J Physiol 261:R1346-R1350

Costanzo JP, Lee RE Jr, Lortz PH (1993a) Glucose concentration regulates freeze tolerance in the wood frog Rana sylvatica. J exp Biol 181:245-255

Costanzo JP, Lee RE Jr, Lortz PH (1993b) Physiological responses of freeze-tolerant and -intolerant frogs: clues to evolution of anuran freeze tolerance. Am J Physiol 265:R721-R725

Costanzo JP, Lee RE Jr, Wright MR (1991a) Effect of cooling rate on the survival of frozen wood frogs. J comp Physiol B $161: 225-229$

Costanzo JP, Lee RE Jr, Wright MR (1991b) Glucose loading prevents freezing injury in rapidly cooled frogs. Am $J$ Physiol 261:R1549-R1553

Costanzo JP, Lee RE Jr, Wright MR (1992a) Cooling rate influences cryoprotectant distribution and organ dehydration in freezing wood frogs. J exp Zool 261:373-378

Costanzo JP, Wright MF, Lee RE Jr (1992b) Freeze tolerance as an overwintering adaptation in Cope's grey tree frog (Hyla chrysoscelis). Copeia 1992:565-569

Duellman WE, Trueb L (1986) Biology of amphibians. Johns Hopkins University Press, Baltimore

Hearne SA (1911) A journey from Prince of Wales' Fort in Hudson's Bay to the Northern Ocean in the years 1769. 1770, 1771, and 1772. Champlain Society, Toronto

Hedges B (1986) An electrophoretic analysis of holarctic hylid frog evolution. Syst Zool 35:1-21

King PA, Rosholt MA, Storey KB (1993) Adaptations of plasma membrane glucose transport facilitate cryoprotectant distribution in freeze tolerant frogs. Am J Physiol 265: R1035-R1042

Kling KB, Costanzo JP, Lee RE Jr (1994) Post-freeze recovery of peripheral nerve function in the freeze-tolerant wood frog, Rana sylvatica. J comp Physiol B 164:316-320

Layne JR Jr (1991) External ice triggers freezing in freeze tolerant frogs at temperatures above their supercooling point. J Herpetol 25:129-130

Layne JR Jr (1992) Postfreeze survival and muscle function in the leopard frog (Rana pipiens) and the wood frog (Rana sylvatica). J therm Biol 17:121-124

Layne JR Jr (1993) Postfreeze recovery of gastrocnemius muscles from the frogs Rana pipiens and $R$. sylvatica. $\mathrm{J}$ Herpetol 27:478-480

Layne JR Jr (1995a) Crystallization temperatures of frogs and their individual organs. J Herpetol (in press) 
Layne JR Jr (1995b) Seasonal varuation in the cryobiology of wood frogs (Rana sylvatica) from western Pennsylvania. $\mathrm{J}$ therm Biol (in press)

Layne JR Jr, First MC (1991) Resumption of physiological functions in the wood frog (Rana sylvatica) following freezing. Am J Physiol 261:R134-R137

Layne JR Jr, Lee RE Jr (1987) Freeze tolerance and the dynamics of ice formation in wood frogs (Rana sylvatica) from southern Ohio. Can J Zool 65:2062-2065

Layne JR Jr, Lee RE Jr (1989) Seasonal variation in freeze tolerance and ice content of the treefrog Hyla versicolor. $J \exp$ Zool 249:133-137

Layne JR Jr, Lee RE Jr, Heil TL (1989) Freezing-induced changes in the heart rate of wood frogs (Rana sylvatıca). Am J Physiol 257:R1046-R1049

Layne JR Jr, Lee RE Jr, Huang JL (1990) Inoculation triggers freezing at high subzero temperatures in a freeze-tolerant frog (Rana sylvatica) and insect (Eurosta solidaginis). Can J Zool 68:506-510

Lee RE Jr, Costanzo JP (1993) Integrated physiological responses promoting anuran freeze tolerance. In: Carey $C$, Florant GL, Wunder BA, Horwitz B (eds) Life in the cold III: Ecological, physiological, and molecular mechanisms. Westview Press, Boulder, CO, p 501-510

Lee RE Jr, Costanzo JP, Davidson EC, Layne JR Jr (1992) Dynamics of body water during freezing and thawing in a freeze tolerant frog (Rana sylvatica). J therm Biol 17 : 263-266

Lee RE Jr, Denlinger DL (eds) (1991) Insects at low temperature. Chapman and Hall, New York.

Lee RE Jr, Layne JR Jr, Costanzo JP, Davidson EC (1990) Systemic and organismal responses to freezing in vertebrates. Cryobiol 27:643-644

Lee RE Jr, McGrath JG, Morason RT, Taddeo RM (1993) Survival of intracellular freezing, lipid coalescence and osmotic fragility in fat body cells of the freeze-tolerant gall fly Eurosta solidaginis. J Insect Physiol 39:445-450

Lotshaw DP (1977) Temperature adaptation and effects of thermal acclimation in Rana sylvatica and Rana catesbeiana. Comp Biochem Physiol 56A:287-294

MacArthur DL, Dandy JWT (1982) Physiological aspects of overwintering in the boreal chorus frog (Pseudacris triseriata maculata). Comp Biochem Physiol 72A:137-141

Mazur P (1984) Freezing of living cells: mechanisms and implications. Am J Physiol 247:C125-C142
Miller LK, Dehlinger PJ (1969) Neuromuscular function at low temperatures in frogs from cold and warm climates. Comp Biochem Physiol 28:915-921

Pinder AW, Storey KB, Ultsch GR (1992) Estivation and hibernation. In: Feder ME, Burggren WW (eds) Environmental physiology of the amphibians. University of Chicago Press, Chicago, p 250-274

Ralin DB, Romano MA, Kilpatrick CW (1983) The tetraploid treefrog Hyla versicolor evidence for a single origin from the diploid $H$. chrysoscelis. Herpetologica 39:212-225

Rubinsky B, Pegg DE (1988) A mathematical model for the freezing process in biological time. Proc $R$ Soc Lond $B$ 234:343-358

Schmid WD (1982) Survival of frogs at low temperature. Science 215:697-98

Schmid WD (1986) Winter ecology. Ekologiya 6:29-35

Storey JM, Storey KB (1985a) Triggering of cryoprotectant synthesis by initiation of ice nucleation in the freeze tolerant frog, Rana sylvatica. J comp Physiol B 156:191-195

Storey JM, Storey KB (1985b) Adaptations of metabolism for freeze tolerance in the gray tree frog, Hyla versicolor. Can J Zool 63:49-54

Storey KB, Baust JG, Wolanczyk JP (1992a) Biochemical modification of plasma ice nucleating activity in a freeze-tolerant frog. Cryobiol 29:374-384

Storey KB, Bischof J, Rubinsky B (1992b) Cryomicroscopic analysis of freezing in liver of the freeze-tolerant wood frog. Am J Physiol 263:R185-R194

Storey KB, Storey JM (1984) Biochemical adaptations for freezing tolerance in the wood frog. Rana sylvatica. J comp Physiol B 155:29-36

Storey KB, Storey JM (1986) Freeze tolerance and intolerance as strategies of winter survival in terrestrially hibernating amphibians. Comp Biochem Physiol 83A, 613-617

Storey KB, Storey JM (1987) Persistence of freeze tolerance in terrestrially hibernating frogs after spring emergence. Copeia 1987:720-726

Storey KB, Storey JM (1992) Natural freeze tolerance in ectothermic vertebrates. A Rev Physiol 54:619-654

Wolanczyk JP, Baust JG, Storey KB (1990a) Seasonal ice nucleating activity in the freeze tolerant frog, Rana sylvatica. Cryo-Lett 11:143-150

Wolanczyk JP, Storey KB, Baust JG (1990b) Ice nucleating activity in the blood of the freeze tolerant frog, Rana sylvatica. Cryobiol 27:328-335 